Virtual Mentor. March 2004, Volume 6, Number 3.

doi: 10.1001/virtualmentor.2004.6.3.jdsc1-0403

Journal Discussion

\title{
Leap-Frogging to Forgiveness
}

\section{A journal author calls for physicians to admit to and repent for their medical mistakes, even in a no-blame environment.}

\author{
Faith Lagay, PhD
}

Berlinger N. Avoiding cheap grace: medical harm, patient safety, and the culture(s) of forgiveness. Hastings Center Report. 2003;33:28-36.

View Article PubMed Google Scholar

The systems approach to reducing medical error has introduced a vocabulary of its own and a new way of thinking about physician accountability. Terms such as "sentinel events," "adverse effects," "near-misses," and "safe systems" reflect the concerted move away from assigning blame for patient harm to individual physicians. Instead, the "root analysis" method used in the systems approach uncovers a series of linked events, actions, or omissions that, taken together, produced an unexpected and unwanted outcome. If something slightly different had been said or done at any one of these linked occasions - if someone had not been called away from his or her post, if the trainee had not been too intimidated to question an order or a dose - the consequent harm would not have occurred.

This approach has proved its worth. Resulting innovations such as computerized physician order entry (CPOE) and unit dosing; patients' signing of their surgery sites and presurgery time-outs in the OR; limited use of abbreviations in orders and charts; bar-coding on patient's armbands and charts; and stricter hand-washing regimes have reduced the numbers of adverse events and demonstrated that every "one" on the team-including the patient and the computerhas a role in patient safety. For root analysis to work, each participant in the chain of events that ultimately ended in an error has to reveal his or her action, omission, or observation without fear of blame or reprisal. Hence, the approach has given rise to a "no-blame" environment. People are encouraged to disclose on the understanding that no one will be blamed for an unintended mistake.

Any methodical approach that reduces medical error and patient harm is to be heralded, but, Nancy Berlinger argues in "Cheap Grace," something is also lost in the no-blame approach [1]. As is obvious from her title, Berlinger looks at accountability and forgiveness for harm to others from a religious perspective-chiefly from the Jewish and Christian faith traditions. She doesn't apologize for taking this view, but she does begin by reminding us that the complementary line to the Institute of Medicine's now famous report title-"To Err Is Human"-is "To forgive, divine." In both the Jewish and Christian faiths, it is indeed God who forgives the sin or error, and the injured party who forgives the sinner. The second half of this forgiveness - the relational, human aspect of forgiveness - is emphasized to a greater degree in the Jewish tradition than in the Christian (eg, in the ritually enacted request by observant Jews for forgiveness from those they have injured each year prior to Yom Kippur) [2]. But both traditions have a 2-part ritual requirement for seeking forgiveness: first, "acknowledgments for the error by the person who has made it" (eg, confession), and, second, an "effort to make amends for the harm" (eg, repentance and atonement) [2].

Berlinger does not advocate that we observe these religious rituals in the secular world of health care-not exactly. But she believes that we omit a crucial component of forgiveness when errors are assumed to be forgiven without an admission of accountability or a perceived need to make amends. Forgiveness without admission, repentance, or attempts at restitution is the "cheap grace" of her title, borrowed from World War II-era German theologian Dietrich Bonhoeffer. Expectations of cheap grace ignore the relational aspect of injury and assume that the injured party should 
forgive, even "in the absence of disclosure, apology, accountability, or compensation" [3]. Berlinger associates the systems-error, no-blame approach with cheap grace. And she thinks that expecting forgiveness without admitting error and attempting to make amends for it can increase the harm done by the initial error. In "dodging" personal responsibility, for example, the systems approach undermines respect for persons and ignores the human suffering (of both the patient and the physician responsible for the injury) caused by the error [4].

The no-blame approach can cause a more serious harm-an inversion of the guilt and forgiveness relationship so that the injured party is accused of moral defect if he or she does not absolve and forgive immediately. Berlinger points to "well-intentioned pastors and other counselors who encourage trauma survivors to forgive abusers who refuse to acknowledge or repent of their actions" [4]. She also refers to studies which show that the ability to forgive is "taken as a marker of psychological health" and that victims of trauma and error who withhold forgiveness are portrayed as having a tendency to "feel hurt" or "take offense" [5]. Here, the victim is considered blameworthy for not granting cheap grace.

Berlinger believes that taking responsibility for injury and repenting (by offering compensation) demonstrates respect for individuals and are necessary components of true relational forgiveness. She suggests that secular counterparts of these religious rituals can be carried over into the world of health care. For the admissibility or taking responsibility step, her suggestions include acknowledging the error; taking personal responsibility for one's role, even in cases of system error; apologizing to injured patients; providing opportunities for clinicians to process the error and receive counseling; and avoiding abuses of power in dealing with both patients and subordinates (eg, not scapegoating) [5]. Practices that can function as repentance include not forcing the injured patient to interact with those responsible for the injury if the patient does not want to; offering injured parties pastoral or other counselor care; "covering the cost of treating injuries that result from the error;" and "working to create conditions that allow patients to detach from the incident as a source of pain, anger, and injustice" [6]. Finally, those practices that promote forgiveness include allowing injured patients to take part in the hospital's quality improvement process; helping clinicians, chaplains, patient advocates, and others understand the psychological aspects of medical error; and "challenging any aspects of institutional culture that deny the fallibility, and therefore the humanity, of health care workers or that work against truth-telling, accountability, compassion, and justice in dealing with medical error and promoting patient safety" [6].

If we wish to reincorporate the notion of individual accountability into the no-blame systems approach, it will be necessary, Berlinger says, to distinguish blame from shame. Humans are fallible. Mistakes testify to our humanity. We become inhuman only if we ignore the harm our mistake has done.

\section{References}

1. Berlinger N. Avoiding cheap grace: medical harm, patient safety, and the culture(s) of forgiveness. Hastings Center Report. 2003;33:28-36.

View Article PubMed Google Scholar

2. Berlinger N, 30 .

3. Berlinger N, 29.

4. Berlinger N, 31 .

5. Berlinger N, 32 .

6. Berlinger N, 33 .

\section{Questions for Discussion}

1. Berlinger describes religious rituals that call for admission of accountability and repentance when one has caused injury to another. Do you think these practices express a psychological need to confess and repent when one has caused harm? In other words, do you think that admitting responsibility and apologizing contribute to the healing and psychological health of clinicians who cause harm to patients? 
2. How do you think Berlinger's suggestion to demand apology and repentance would be received in the secular world of health care? Are the actions that she suggests as secular equivalents-eg, apologizing to the patient, allowing the patient to not interact with the person responsible for the injury, covering the cost of treating injuries that result from the error-reasonable expectations in a nonreligious setting?

The viewpoints expressed on this site are those of the authors and do not necessarily reflect the views and policies of the AMA.

(C) 2004 American Medical Association. All Rights Reserved. 